\section{Check for updates}

Cite this: J. Mater. Chem. A, 2021, 9, 5578

Received 31st August 2020

Accepted 18th January 2021

DOI: $10.1039 / \mathrm{d} 0 \operatorname{ta} 08551 \mathrm{k}$

rsc.li/materials-a

\title{
Au integrated AgPt nanorods for the oxygen reduction reaction in proton exchange membrane fuel cells $\uparrow$
}

\author{
Elok Fidiani, ${ }^{\text {ac }}$ Gnanavel Thirunavukkarasu, ${ }^{\mathrm{b}}$ Yang Li, ${ }^{\mathrm{a}} \mathrm{Yu}$-Lung Chiu ${ }^{\mathrm{b}}$ \\ and Shangfeng Du (iD *a
}

\begin{abstract}
The development of new electrode fabrication approaches from highly active electrocatalysts to replace the state-of-the-art $\mathrm{Pt} / \mathrm{C}$ is most desirable for enhancing power performance and durability in proton exchange membrane fuel cells. However, the deployment of advanced, often shape-controlled Pt alloy electrocatalysts in actual electrodes remains challenging due to their small quantities in preparation and poor power performance in operating fuel cells. In this study, a new electrocatalyst approach is presented for Au integrated one-dimensional AgPt alloy nanorods. The atom arrangement is tuned through precisely controlling the metal ion reduction procedure to improve the catalyst activity. With 5 at\% Au, nanorods with an average length of $20 \mathrm{~nm}$ and diameter of 3-4 nm are achieved. The test of $\mathrm{Au}$-AgPt nanorods as cathode catalysts shows 1.2-fold higher fuel cell power density than that for commercial Pt/C catalysts, and a lower decline rate of $39.63 \%$ than $44.19 \%$ after an accelerated degradation test.
\end{abstract}

\section{Introduction}

Proton exchange membrane fuel cells (PEMFCs) are attractive power generators for transportation and stationary applications due to their low operating temperature, high power density and easy start-up and shutdown. ${ }^{1}$ The intense development during past years has moved this technology to successful commercialization. ${ }^{2}$ However, the requirement of a high loading of platinum (Pt) catalysts for promoting the oxygen reduction reaction (ORR) at the cathode demotes the economic benefit of

${ }^{a}$ School of Chemical Engineering, University of Birmingham, Birmingham, B15 2TT, UK. E-mail: s.du@bham.ac.uk

${ }^{b}$ School of Metallurgy and Materials, University of Birmingham, Birmingham, B15 2TT, UK

'Department of Physics, Parahyangan Catholic University, Jl. Ciumbuleuit 94, Bandung 40141, Indonesia

$\dagger$ Electronic supplementary information (ESI) available: HRTEM images and EDX analysis results of Au-AgPt NR/C B, TEM images of Au-AgPt NR/C synthesized following reaction scheme $\mathrm{A}$ with different $\mathrm{Au}$ contents and the corresponding TGA and ICP-MS analysis results. XRD patterns and high resolution XPS peaks of the Pt and $\mathrm{Ag}$ regions of $\mathrm{Au}-\mathrm{AgPt} \mathrm{NR} / \mathrm{C}$ with different $\mathrm{Au}$ at\% synthesized following reaction scheme A, including a table summarizing the compositions of the as-prepared catalysts. EIS spectra measured at 0.65 and $0.5 \mathrm{~V}$ of the as-prepared catalysts. MEA testing results of $\mathrm{Au}-\mathrm{AgPt} \mathrm{NR} / \mathrm{C} \mathrm{A}$ with varied $\mathrm{Au}$ at\% benchmarked against Pt NR/C and AgPt NR/C, presented with the cathode CVs and corresponding ECSA comparison. The results of the RDE measurement and the plots to determine the internal ohmic resistance hydrogen crossover current density. The recorded polarization, power density curves and cathode CVs of Pt NRs, AgPt NR/C and Au-AgPt NR/C A with different $\mathrm{Au}$ at $\%$ after the ADT. See DOI: 10.1039/d0ta08551k this technology and makes it less competitive in the market. ${ }^{3}$ The ultimate strategies to reduce Pt loading while improving the catalytic performance have been reviewed via alloying Pt with less expensive metals such as Co or Ni. ${ }^{4-6}$ However, stability is another challenge with the alloyed metals under severe acidic operating conditions within PEMFCs. ${ }^{7-10}$ Furthermore, the zerodimensional (0D) nanoparticle (NP) structure is also a contributing factor towards catalyst degradation during long-term use, which is triggered by susceptibility of the small NPs to dissolution and aggregation. ${ }^{11,12}$

To date, single-crystal 1D catalyst nanostructures such as nanowires (NWs) and nanorods (NRs) attract huge attention for overcoming the deficiency of $0 \mathrm{D}$ NP catalysts for PEMFC applications. ${ }^{13-16}$ The defect-free structure and lower surface energy derived from the 1D contexture provide higher resistance against degradation for better durability. ${ }^{17}$ 1D Pt-alloy catalysts with precious and non-precious metals such as Pd, $\mathrm{Au}, \mathrm{Ag}, \mathrm{Cu}$ and $\mathrm{Ni}$ have demonstrated enhanced catalytic activities and stability towards the ORR..$^{13,18-21}$ However, a facile production of 1D Pt-alloy nanostructures is highly challenging due to the requirements of templates or capping agents, usually limiting their synthesis to the microgram order. Such a small amount is only available for half-cell rotating disk electrode (RDE) measurement in liquid electrolytes and very few research studies reported their applications in real catalyst electrodes for PEMFCs. $^{22,23}$

With a facile formic acid reduction method, 1D AgPt nanostructures have been successfully synthesized and demonstrated for the ORR application. ${ }^{24}$ Compared with Pt, the cost of 
$\mathrm{Ag}$ is very low $(<2 \% c f$. $\mathrm{Pt})$, which is an advantage for the commercial purpose. Ag also possesses a similar standard reduction potential (SRP) and lattice constant to $\mathrm{Pt}$, making it easy to alloy with Pt by wet chemical reduction methods. A similar lattice constant is an advantage to induce the synergy between $\mathrm{Ag}$ and Pt interaction, promoting the catalytic activity and preventing segregation for better stability. ${ }^{25}$ Although the Pt@Ag core-shell NRs have been reported to exhibit good stability in the RDE electrochemical measurement, ${ }^{26}$ the testing in fuel cells showed that the dissolution of $\mathrm{Ag}$ from AgPt alloy electrocatalysts was unavoidable during PEMFC operation, resulting in a dramatic power performance decline. ${ }^{24}$

Besides Ag, among the commonly used alloy metals with Pt, $\mathrm{Au}$ has been known as an effective doping metal for enhancing the stability of alloy catalysts. ${ }^{27-30}$ The presence of Au clusters can provide a stabilization effect through the electronic structure modification of the Pt-based catalysts, preventing oxide formation on the Pt surface. ${ }^{31-33}$ Meanwhile, the charge transfer effect induced by introducing a small number of $\mathrm{Au}$ atoms can potentially reduce the formation of unstable high-energy $\mathrm{Pt}$ sites, improving stability under the ORR conditions. ${ }^{34}$ It also stabilizes the catalyst by weakening the binding of oxygen species on the catalyst surface, thus suppressing the segregation of alloyed metals such as Pd, Co and Ni. ${ }^{27,33,35}$ Therefore, the integration of $\mathrm{Au}$ with AgPt to develop 1D alloy catalysts can be a promising strategy to upgrade the catalytic activity and stability for practical application in PEMFCs.

In this work, we explore the self-growth formic acid reduction method to control the formation of 1D Au-AgPt alloy nanostructures, considering that the stabilization effect of $\mathrm{Au}$ is highly affected by the catalyst structure, composition and elemental distribution. ${ }^{\mathbf{3 0 , 3 4}}$ The influence mechanisms of Au on the morphology, structure and catalytic performance are thoroughly investigated based on the physical characterization and PEMFC test results. The optimal Au content is determined, and the enhanced durability of the Au-AgPt catalyst electrodes is also demonstrated based on the accelerated degradation test (ADT) results in PEMFCs.

\section{Experimental}

\section{Materials}

All materials were used as received without additional treatment and purification, including carbon black Vulcan XC-72R (FuelCellStore, USA), $\mathrm{H}_{2} \mathrm{PtCl}_{6}$ (8 wt\% in $\mathrm{H}_{2} \mathrm{O}$ ), $0.1 \mathrm{M} \mathrm{AgNO}_{3}, \mathrm{HAuCl}_{4}{ }^{-}$ $\cdot 3 \mathrm{H}_{2} \mathrm{O}$ and $\mathrm{HCOOH}(\geq 95 \%)$ (Sigma-Aldrich, UK), ethanol and 2propanol (IPA) (Fisher Scientific, UK), and $10 \mathrm{wt} \%$ Nafion ${ }^{\circledR}$ polymer dispersion (D1021) (Ion Power Inc., USA). The water used was deionized (DI) to $18 \mathrm{M} \Omega \mathrm{cm}$ using a Millipore water system, MilliQ. And as a benchmark, a commercial Pt/C nanoparticle catalyst (46.2 wt\% Pt, TEC10E50E, TKK, Japan) was used.

\section{Growing Au-AgPt alloy nanorods on carbon}

Typically, for the synthesis of the 5 at $\%$ Au integrated AgPt NR/C A catalyst (Au-AgPt NR/C A), 1 mL of $\mathrm{H}_{2} \mathrm{PtCl}_{6}\left(8 \mathrm{wt} \%\right.$ in $\mathrm{H}_{2} \mathrm{O}$ ) in $50 \mathrm{~mL}$ water was added to $100 \mathrm{~mL}$ water containing $50 \mathrm{mg}$ of carbon black. $10 \mathrm{~mL}$ of $\mathrm{HCOOH}$ was subsequently added dropwise under sonication for up to 10 minutes. $1 \mathrm{~mL}$ of $25 \mathrm{mM}$ $\mathrm{HAuCl}_{4}$ was then added under stirring. The stirring was continued at room temperature for $c a$. 5 hours and then $1.7 \mathrm{~mL}$ of $0.1 \mathrm{M} \mathrm{AgNO}_{3}$ in $50 \mathrm{~mL}$ of water was added. The reaction was continued under stirring for up to 96 hours at room temperature. The final product was then washed with water and ethanol, followed by drying in an oven $\left(60{ }^{\circ} \mathrm{C}, 2 \mathrm{~h}\right)$. The different $\mathrm{Au}$ contents were achieved by changing the concentration of $\mathrm{Au}$ and Ag precursors while keeping the Pt and total metal loading constant.

\section{Physical characterization}

The structure and morphology of the catalysts were analyzed using a transmission electron microscope (JEOL 1400 TEM, 80 $\mathrm{kV}$, Japan) and a high-resolution TEM (HR-TEM, Talos F200X, operated at $200 \mathrm{kV}$ ) equipped with a super-X EDS system with four silicon drift detectors (SDDs) (Bruker, USA). Thermogravimetric analysis (TGA, NETZSCH TG209F1, Germany) was conducted between 20 and $900{ }^{\circ} \mathrm{C}$ to determine the metal loading on carbon. The metal component was quantified with inductively coupled plasma mass spectrometry (ICP-MS, Perkin Elmer Nexion 300X, USA) (plasma strength of $1500 \mathrm{~W}$ ). Powder X-ray diffraction (XRD) analysis was performed with a D8 Autosampler Bruker (USA) equipped with a $\mathrm{Cu} \mathrm{K} \alpha \mathrm{X}$-ray source $(\lambda$ $=0.15406 \mathrm{~nm}$ ) to determine the crystal structure of the catalysts. X-ray photoelectron spectroscopy (XPS, Thermo Fisher Scientific NEXSA spectrometer) with a micro-focused monochromatic $\mathrm{Al} \mathrm{K} \alpha$ source ( $72 \mathrm{~W}$ ) was used to evaluate the surface composition and oxidation state of catalysts. The XPS data analysis was processed using CasaXPS software (version: 2.3.18PR1.0) and sample charging corrected using the $\mathrm{C} 1 \mathrm{~s}$ peak at $284.8 \mathrm{eV}$ as a reference.

\section{Half-cell rotating disk electrode (RDE) measurement}

Half-cell electrochemical measurement was conducted using the RDE method on an Autolab PGSTAT302N Potentiostat (Metrohm Ltd, UK), with a glassy carbon electrode (GCE; 0.196 $\mathrm{cm}^{2}$ ) of Pine Research Instrumentation Inc., USA. For each measurement, $5 \mu \mathrm{L}$ of catalyst ink was deposited on the GCE. The ink solution was made of about $5 \mathrm{mg}$ of catalyst powder dispersed in $780 \mu \mathrm{L}$ of $\mathrm{H}_{2} \mathrm{O}, 200 \mu \mathrm{L}$ of IPA and $20 \mu \mathrm{L}$ of $10 \mathrm{wt} \%$ Nafion ${ }^{\circledR}$ dispersion. To obtain a homogeneous catalyst ink, a sonication probe (A Sonics Vibra-CellTM VCX130, USA) was applied at a power amplitude of $20 \%$. Cyclic voltammetry (CV) measurement was carried out in $\mathrm{N}_{2}$ saturated $0.1 \mathrm{M} \mathrm{HClO}_{4}(\mathrm{aq})$ at $25{ }^{\circ} \mathrm{C}$ between 0.05 and $1.2 \mathrm{~V}$ vs. RHE. Cleaning was first performed with $50 \mathrm{CV}$ cycles at a scan rate of $100 \mathrm{mV} \mathrm{s}^{-1}$, followed by 3 cycles at a slow scan rate of $20 \mathrm{mV} \mathrm{s}^{-1}$ to estimate the electrochemical surface area (ECSA) of the catalysts. The electrochemical impedance spectroscopy (EIS) analysis was performed in the frequency range of $0.1 \mathrm{~Hz}$ to $100 \mathrm{kHz}$ with an amplitude of $10 \mathrm{mV}$. Linear sweep voltammetry (LSV) analysis was run from $0.05-1.2 \mathrm{~V} v$ s. RHE at a scan rate of $20 \mathrm{mV} \mathrm{s}^{-1}$ and a rotation speed of $1600 \mathrm{rpm}$ in an $\mathrm{O}_{2}$ saturated electrolyte. Specific and mass activities were calculated by normalising the 
kinetics current obtained at $0.9 \mathrm{~V}$ with respect to the ECSA and Pt mass of the catalysts.

\section{MEA fabrication and fuel cell testing}

The catalyst ink for the cathode was made of $0.5 \mathrm{~mL}$ IPA, $45.7 \mu \mathrm{L}$ of $10 \mathrm{wt} \%$ Nafion $^{\mathrm{TM}}$ dispersion and the catalyst powder with a $\mathrm{Pt}$ loading of $0.2 \mathrm{mg}_{\mathrm{Pt}} \mathrm{cm}^{-2}$. The sonication probe was used at a power amplitude of $20 \%$ to obtain a fine dispersion of the catalyst ink. The ink was then painted onto a piece of $4 \times 4 \mathrm{~cm}^{2}$ Sigracet $39 \mathrm{BC}$ gas diffusion layer (GDL) and then left to dry for 2 hours at $35{ }^{\circ} \mathrm{C}$. The membrane electrode assembly (MEA) was fabricated by assembling the as-prepared cathode, a commercial gas diffusion electrode (GDE, $0.2 \mathrm{mg}_{\mathrm{Pt}} \mathrm{cm}^{-2}$, FuelCellStore USA) as the anode and a $6 \times 6 \mathrm{~cm}^{2}$ Nafion 212 membrane hotpressed under $1800 \mathrm{lb}$ load for 2 minutes at $135^{\circ} \mathrm{C}$.

A Biologic-PaxiTech FCT-50S PEM fuel cell test rig (France) was employed for the MEA test. Polytetrafluoroethylene (PTFE, $254 \mu \mathrm{m}$ in thickness) gaskets were used at both the anode and cathode sides. The membrane hydration was carried out by holding at $0.6 \mathrm{~V}$ for at least 12 hours under fully humidified $\mathrm{H}_{2}$ / air at $80^{\circ} \mathrm{C}$ and a stoichiometric ratio of $1.3 / 1.5$ with an absolute pressure of 1.5/1.5 bar at the anode and cathode, respectively. A cell break-in procedure was then conducted by following the harmonized EU protocols under fully humidified $\mathrm{H}_{2}$ /air at $80{ }^{\circ} \mathrm{C}$ and a stoichiometric ratio of 1.3/1.5 with an absolute pressure of 2.5/2.3 bar at the anode and cathode, respectively. ${ }^{36}$ The standard deviation of three repeated tests was applied to determine the error bars for the peak power density. EIS analysis was then conducted at $30 \mathrm{~mA} \mathrm{~cm}{ }^{-2}, 0.65 \mathrm{~V}$ and $0.5 \mathrm{~V}$, with an amplitude of $4.5 \mathrm{~mA} \mathrm{~cm}{ }^{-2}, 10 \mathrm{mV}$ and $10 \mathrm{mV}$, respectively, in the frequency range of $10 \mathrm{kHz}$ to $0.1 \mathrm{~Hz}$. Potentio EIS (PEIS) at $0.65 \mathrm{~V}$ and $0.5 \mathrm{~V}$ rather than Galvano EIS (GEIS) at a large current density was selected here because for some poor catalysts/GDEs, a large current density (e.g. $1.0 \mathrm{~A} \mathrm{~cm}^{-2}$ ) could not be reached.
To monitor the ORR mass activity of the catalyst in the MEA, the cathode gas was switched to $\mathrm{O}_{2}$, and the stoichiometry ratio of the anode/cathode was changed to $2 / 9.5$ at $1.5 / 1.5$ bar $_{\text {abs }}$, respectively, following the U.S DoE standard conditions. The same method of cell break-in procedure and recording polarization curve as that in $\mathrm{H}_{2}$ /air was applied. For correction, the internal resistance was determined using GEIS obtained from the low-current density at the high-frequency range, and the $\mathrm{H}_{2}$ crossover current was obtained by holding the potential at $0.5 \mathrm{~V}$ with the $\mathrm{N}_{2}$ saturated cathode for 30 minutes using an EZStatPro potentiostat (NuVant Systems Inc., USA). The measured current at $0.9 \mathrm{~V}$ from the corrected polarisation curve was then applied to calculate the mass and specific activities. CV curves were also recorded using the EZStat-Pro potentiostat between 0.05 and $1.2 \mathrm{~V}$ at a scan rate of $20 \mathrm{mV} \mathrm{s}^{-1}$. The standard deviation of three repeated $\mathrm{CV}$ plots was applied to estimate the error bars of the ECSA. An accelerated degradation test (ADT) of the cathode was conducted using a potential sweeping method between 0.6 and $1.2 \mathrm{~V}$ at a scan rate of $100 \mathrm{mV} \mathrm{s}^{-1}$ for 5000 cycles. The polarization curves and CVs were recorded after the ADT to evaluate the electrode durability.

\section{Results and discussion}

In this work, the integration of $\mathrm{Au}$ with the $\mathrm{AgPt} \mathrm{NR} / \mathrm{C}$ catalyst was conducted via the formic acid reduction method, for which the reduction potentials of the metal ions are carefully considered for controlling the reaction rate to obtain the expected 1D nanostructures. Based on our previous studies, the initial formation of Pt seeds is crucial to induce the growth of the alloyed metals in a specific direction to form 1D nanostructures. ${ }^{24} \mathrm{Pt}$ and $\mathrm{Ag}$ ions have very similar standard reduction potentials $\left(\left[\mathrm{PtCl}_{4}{ }^{2-} / \mathrm{Pt}^{0}\right]=0.74 \mathrm{~V}\right.$ vs. SHE and $\left[\mathrm{Ag}^{+} / \mathrm{Ag}^{0}\right]=0.79 \mathrm{~V}$ vs. SHE). Hence, the Pt ions are required to be first reduced to form nanoseeds inducing the later crystal growth to form $1 \mathrm{D}$ nanostructures before introducing $\mathrm{Ag}$ ions into the reaction

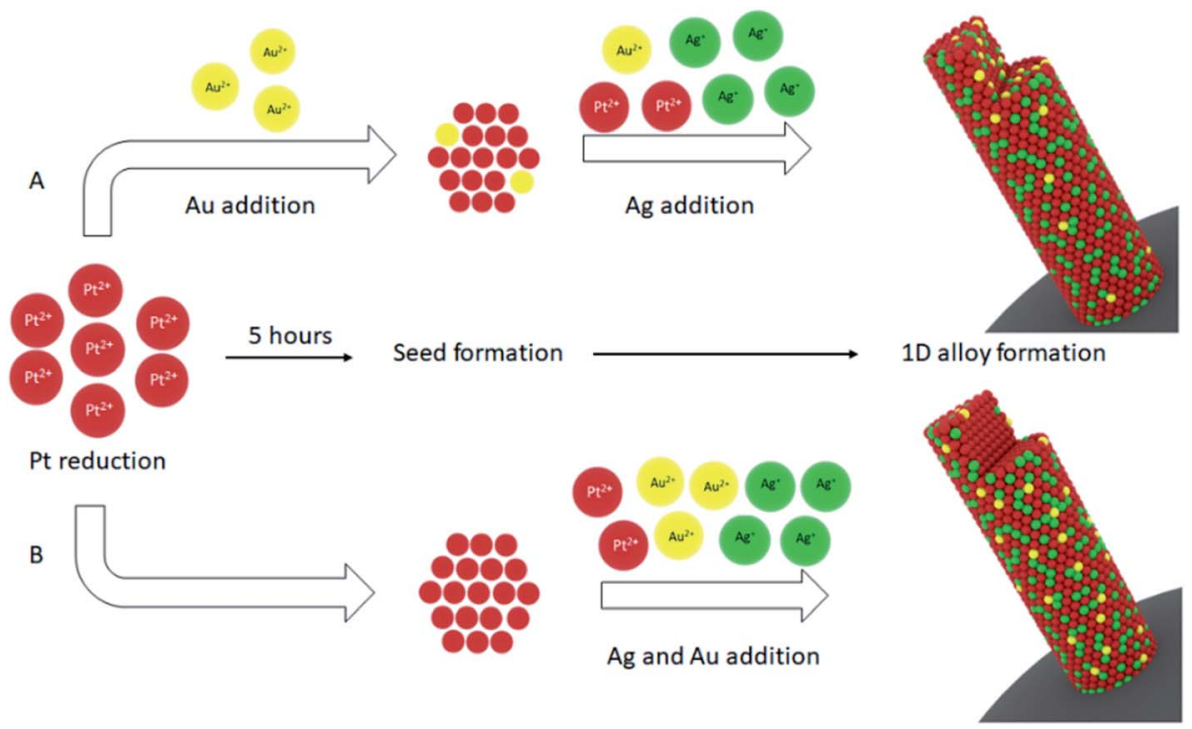

Fig. 1 The synthesis scheme of Au-AgPt NR/C via the formic acid reduction method (the top parts of the NRs are cut to show the element distribution). 
solution. As the stabilization material, the distribution of $\mathrm{Au}$ within the AgPt NRs is crucial, which also influences the catalytic activity of the catalyst. According to Zhang et al., the attachment of $\mathrm{Au}$ on the catalyst surface decreases its catalytic activity as $\mathrm{Au}$ atoms potentially block the active sites (e.g. ORR active sites on Pt). ${ }^{31}$ Meanwhile, the Au stabilizing effect is not severely prevented by displacing it beneath the top atom surface. ${ }^{35}$ Therefore, to achieve a highly active and stable catalyst, the deposition of Au is investigated through controlling the interval time of adding the Au precursor along with the growth of the 1D AgPt alloy NRs, which is schematically shown in Fig. 1.

The introduction of $\mathrm{Au}$ ions at the early reaction stage (Fig. 1, scheme A) leads to the formation of ultrathin harmonized alloy NRs with an average diameter of 3-4 nm and length of $\sim 20 \mathrm{~nm}$ on the carbon support, which is shown by TEM and STEM-EDX analysis results in Fig. 2a. The HRTEM image exhibits a single $\mathrm{NR}$ with an interplanar spacing of $0.23 \mathrm{~nm}$ (Fig. 2c), which is close to the lattice spacing of (111) planes of bulk Pt - JCPDS: 040802 (0.227 nm), Ag - JCPDS: 04-0783 (0.235 nm) and Au JCPDS: 04-0784 $(0.235 \mathrm{~nm})$, indicating the growth along the $\langle 111\rangle$ crystal direction. A uniform lattice orientation shown in the image is expected due to the similar lattice constants of Ag, $\mathrm{Pt}$ and $\mathrm{Au}$, which also signify the harmonized alloy structure of the NRs. The STEM-EDX mapping results show the distribution of Pt, $\mathrm{Ag}$ and $\mathrm{Au}$ within the NRs (Fig. $2 \mathrm{~d}-\mathrm{g}$ ). The overlay element map exhibits a homogeneous distribution of three elements without any boundary, representing good alloying behavior within the NRs. Meanwhile, by delaying the Au addition together with the introduction of the Ag precursor (Fig. 1, scheme B), more Au and $\mathrm{Ag}$ atoms deposit on the outer surface of the NRs, as shown in Fig. S1c. $\dagger$ This morphology potentially reduces the exposure of Pt active sites inducing a lower ECSA. ${ }^{31}$ These results thus confirm the importance of controlling the reduction process of various metal ions to derive $1 \mathrm{D}$ multimetallic alloy nanostructures using the formic acid reduction method.

With the formic acid reduction method, the growth of $1 \mathrm{D} \mathrm{Pt}$ nanostructures is based on a slow reaction rate and selectively weaker adsorption of formate anion species (produced from the slow dehydration of formic acid) on the Pt (111) surface. ${ }^{37}$ As shown in Fig. S2, $\uparrow$ the replacement of 50 at\% Pt with $\mathrm{Ag}$ results in the domination of shorter NRs. This outcome is derived by the change of the reaction rate due to the different reduction potentials of $\mathrm{Pt}$ and $\mathrm{Ag}$ ions, which has been carefully studied in our previous work. ${ }^{24}$ Compared with $\mathrm{Pt}$ and $\mathrm{Ag}$ ions, the higher redox potential of $\mathrm{Au}\left(\left[\mathrm{AuCl}_{4}{ }^{-} / \mathrm{Au}^{0}\right]=0.93 \mathrm{~V} v s\right.$. SHE) (cf. Pt and $\mathrm{Ag}$ ions) implies a much faster chemical reduction rate under the same environmental conditions. Thus, the introduction of the Au precursor with $\mathrm{Pt}$ ions causes dominant $\mathrm{Au}$ reduction in the early reaction period (Fig. 1, scheme A) further slowing down the Pt reduction process. ${ }^{38}$ This induces the growth of longer NRs (Fig. S2 $\dagger$ ) and more Pt deposition on the surface. On the other hand, if Pt ions are left to react for 5 hours at first (Fig. 1, scheme B), some of them are reduced and form Pt seeds. ${ }^{39}$ The introduction of $\mathrm{Au}$ ions at this point induces a slower $\mathrm{Ag}$ reduction and prevents the embedding of $\mathrm{Ag}$ in the inner side of the NRs. Consequently, most $\mathrm{Au}$ and $\mathrm{Ag}$ are attached at the outer atomic layers of the NRs, as shown in Fig. S1c. $\dagger$ Although the ratio of Au is much smaller than that of $\mathrm{Pt}$ and $\mathrm{Ag}$, the reaction kinetics is slow enough in the reduction

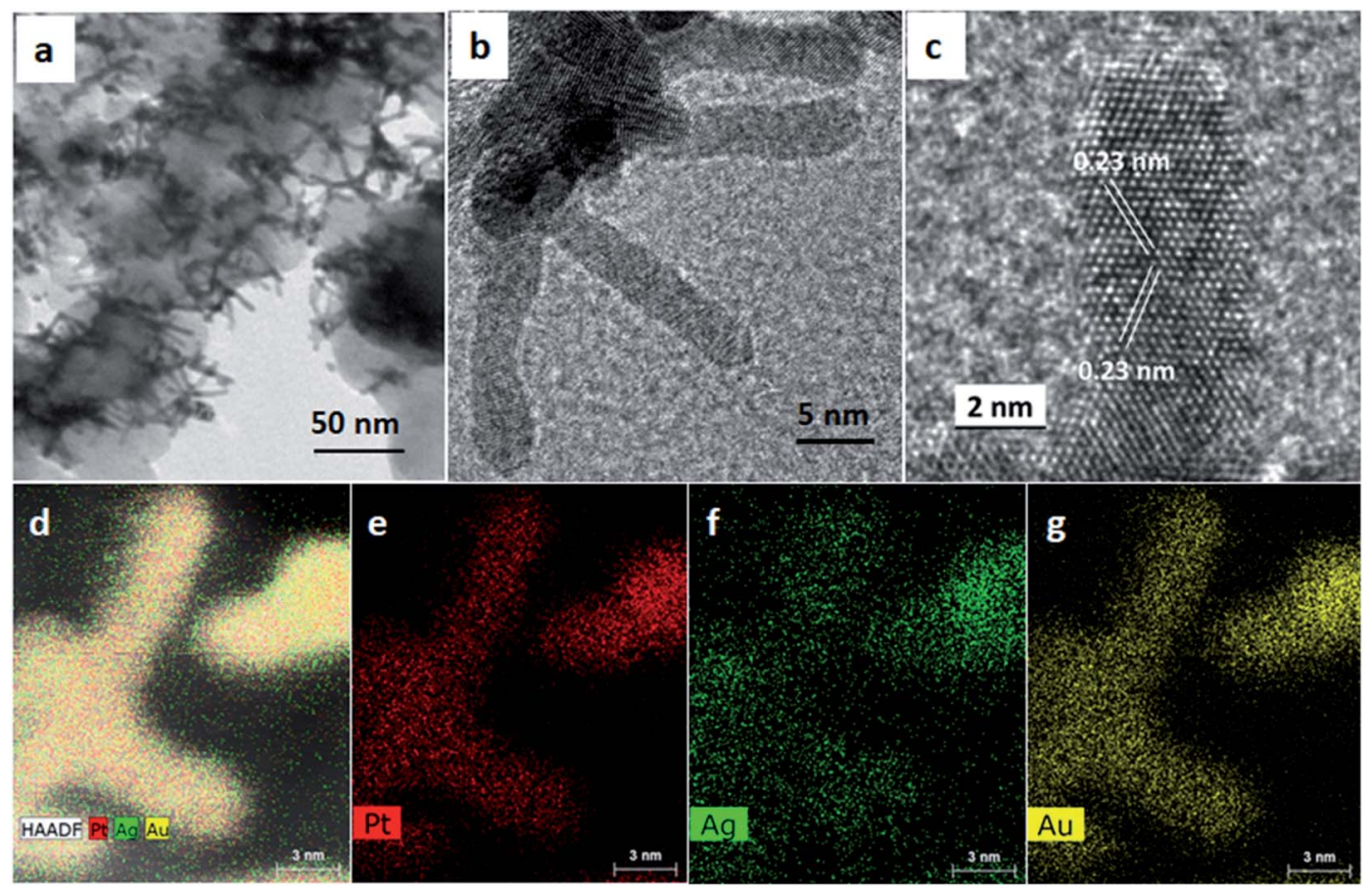

Fig. 2 (a-c) TEM and HR-TEM images of the Au-AgPt NR/C A catalyst synthesized following reaction scheme A, and ( $d-g$ ) show the element mapping by STEM-EDX analysis. 
reaction system when using a weak reducing agent, such as formic acid here. Therefore, a small amount of $\mathrm{Au}$ (i.e. ca. 5 at\%) plays a significant role in changing the chemical reaction rate for the formation of longer NRs (Table 1).

The peaks in the XRD patterns of the AgPt NR/C and 5 at $\%$ $\mathrm{Au}$ integrated $\mathrm{AgPt} \mathrm{NR} / \mathrm{C}$ catalysts are successfully indexed to (111), (200), (220) and (311) planes (Fig. 3a). These are the typical face-centered cubic (fcc) structures of $\mathrm{Pt}, \mathrm{Ag}$ and $\mathrm{Au}$ based on the references of Pt (JCPDS: 04-0802), Ag (JCPDS: 040783) and $\mathrm{Au}$ (JCPDS: 04-0784), respectively. All the peaks for $\mathrm{AgPt} \mathrm{NR} / \mathrm{C}$ and $\mathrm{Au}-\mathrm{AgPt} \mathrm{NR} / \mathrm{C}$ show a negative shift $\left(\mathrm{ca} \cdot 0.1-0.2^{\circ}\right)$ compared with those from Pt (JCPDS: 04-0802). This indicates a change of the lattice spacing due to the alloying with $\mathrm{Ag}$ and $\mathrm{Au}$. The increased peak intensity and reduced full width at half maximum (FWHM) after the introduction of $\mathrm{Au}$ ( $c f . \mathrm{AgPt} \mathrm{NR} / \mathrm{C}$ ) can be ascribed to the improved crystallinity resulting from the longer NRs, which is in agreement with the TEM analysis results (Fig. S2†).

The introduction of $\mathrm{Au}$ also leads to a weakened $\mathrm{Ag}$ (111) peak at $38.35^{\circ}$, indicating a reduced $\mathrm{Ag}$ metal phase. This peak decline is very weak for $\mathrm{Au}-\mathrm{AgPt} \mathrm{NR} / \mathrm{C} \mathrm{B}$ tuned by reducing together more $\mathrm{Au}$ with $\mathrm{Ag}$ and the remaining Pt ions during the second reduction step. The addition of Au and Ag together slows down the $\mathrm{Ag}$ ion reduction rate preventing the formation of the Ag metal phase (Fig. 1, scheme B). ${ }^{24}$ And this tuning effect from $\mathrm{Au}$ is also demonstrated for the catalysts synthesized with a higher Au content by following reaction scheme A, where the Ag metal peak decreases with increasing Au content (Fig. S3†). These findings agree with the mechanism discussed above, and indicate that the alloying degree of $\mathrm{Au}-\mathrm{AgPt} \mathrm{NR} / \mathrm{C}$ can be adjusted by both controlling the interval time of introducing the $\mathrm{Au}$ ions and changing the atomic ratio of Au. The metal contents of the catalysts with various $\mathrm{Au}$ contents were also evaluated using ICP-MS along with TGA analysis and the results are presented in Table S1, $\uparrow$ showing a good agreement with the theoretical value.

A comparison of the surface compositions (Table 1) deduced from the XPS analysis (Fig. 3b) confirms a higher ratio of Pt deposition caused by the introduction of Au. A very small amount of $\mathrm{Au}(0.26 \%)$ was detected on the surface of $\mathrm{Au}-\mathrm{AgPt} \mathrm{NR} / \mathrm{C} \mathrm{A}$, whereas a higher Au composition of 4.34 at\% is obtained for $\mathrm{Au}-$ AgPt NR/C B. Hence, significant $A u 4 f_{7 / 2}$ and $4 f_{5 / 2}$ peaks are observed at 83.46 and $87.12 \mathrm{eV}$, respectively, close to the highresolution Pt 4 f region (Fig. 3c). This further confirms the higher Au content on the NR surface synthesized according to reaction scheme B, which agrees well with the TEM analysis results in
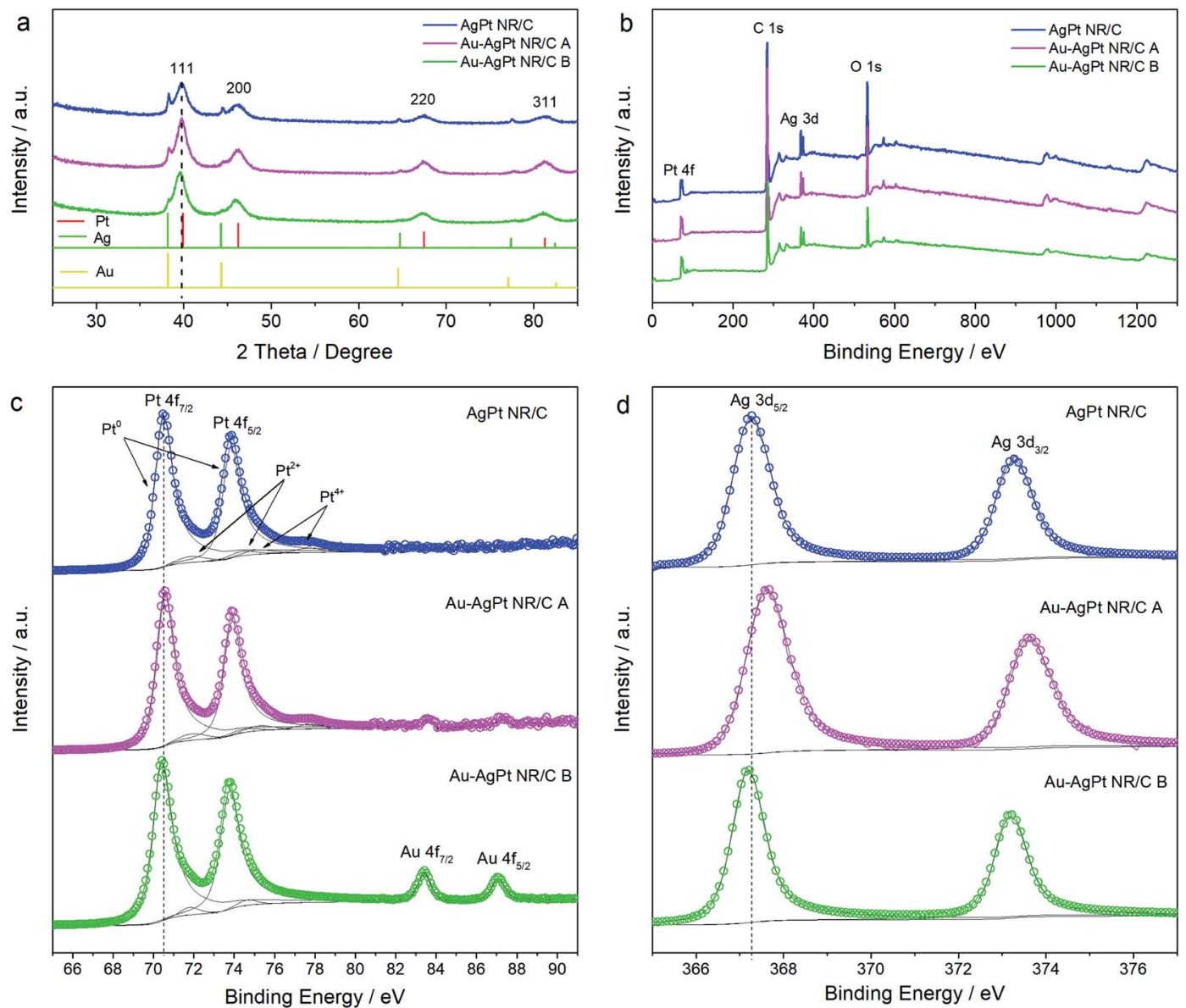

Fig. 3 (a) XRD and (b) XPS patterns of the AgPt NR/C and Au-AgPt NR/C catalysts. The corresponding high-resolution XPS spectra of (c) Pt $4 f$ and (d) Ag 3d regions. 
Table 1 The catalysts size deduced from the TEM analysis results and metal compositions determined by the ICP-MS and XPS analyses of the asprepared catalysts

\begin{tabular}{|c|c|c|c|c|c|c|c|c|c|c|c|}
\hline \multirow[b]{2}{*}{ Catalysts } & \multicolumn{2}{|l|}{ Size/nm } & \multicolumn{3}{|c|}{ ICP-MS/wt\% } & \multicolumn{3}{|c|}{ ICP-MS/at\% } & \multicolumn{3}{|c|}{ XPS/at\% } \\
\hline & $d$ & $l$ & $\mathrm{Au}$ & $\mathrm{Ag}$ & $\mathrm{Pt}$ & $\mathrm{Au}$ & $\mathrm{Ag}$ & $\mathrm{Pt}$ & $\mathrm{Au}$ & $\mathrm{Ag}$ & $\mathrm{Pt}$ \\
\hline $\mathrm{Au}-\mathrm{AgPt}$ NR/C A & $4 \pm 0.5$ & $20 \pm 2$ & 6.77 & 28.56 & 64.67 & 5.45 & 41.97 & 52.58 & 0.26 & 41.68 & 58.06 \\
\hline $\mathrm{Au}-\mathrm{AgPt} \mathrm{NR} / \mathrm{C} \mathrm{B}$ & $4 \pm 0.5$ & $20 \pm 2$ & 6.12 & 27.55 & 66.33 & 4.96 & 40.77 & 54.27 & 4.34 & 43.17 & 52.49 \\
\hline
\end{tabular}

Fig. 2. Nevertheless, the $\mathrm{Au}$ if signals become stronger with a higher Au content, e.g. strong signals are recorded for $12 \mathrm{at} \% \mathrm{Au}$ even with the catalyst synthesized according to reaction scheme A (Fig. S4 $\dagger$ ). The fitting of the two Pt $4 \mathrm{f}$ peaks shows the domination of $\mathrm{Pt}^{0}$ with the characteristic $\mathrm{Pt} 4 \mathrm{f}_{7 / 2}$ and $\mathrm{Pt} 4 \mathrm{f}_{5 / 2}$ peaks (Table $\mathrm{S} 2 \dagger$ ), which are recorded at 70.60 and $73.88 \mathrm{eV}$ for $\mathrm{Au}-\mathrm{AgPt} \mathrm{NR} / \mathrm{C} \mathrm{A}$ and 70.42 and $73.72 \mathrm{eV}$ for $\mathrm{Au}-\mathrm{AgPt} \mathrm{NR} / \mathrm{C} \mathrm{B}$, respectively (Fig. 3c). Similarly, the two $\mathrm{Ag} 3 \mathrm{~d}$ peaks are completely fitted with the metallic state of $\mathrm{Ag}^{0}$ (Table $\mathrm{S} 2 \dagger$ ), and a positive shift is recorded for $\mathrm{Au}-\mathrm{AgPt} \mathrm{NR} / \mathrm{C} \mathrm{A}$ with $\mathrm{Ag} 3 \mathrm{~d}_{5 / 2}$ at $367.58 \mathrm{eV}$ compared to the $367.34 \mathrm{eV}$ for Au-AgPt NR/C B (Fig. 3d). Generally, the binding energies of the main elements of both Au-AgPt NR/C catalysts shift negatively compared to those for the monometallic $\mathrm{Pt}, \mathrm{Ag}$ and $\mathrm{Au}$ (Fig. S4 and S5 $\dagger$ ). However, the shifting degree is varied depending on the Au ratio and deposition, which is related to the charge transfer phenomenon due to the interaction of the multi-metallic structure. ${ }^{40}$ The electronic interaction such as electron transfer from the metal atoms results in the change of the binding energies, which further confirms the modified electronic properties of the AgPt alloy catalyst because of the Au integration. ${ }^{41}$

An MEA test was conducted to evaluate the practical catalytic performance of the as-prepared catalysts toward the ORR in the PEMFC cathode. Fig. 4a shows the polarization and power density curves of the MEAs with the cathode catalyst made of AgPt NR/C, 5 at\% Au-AgPt NR/C and commercial Pt/C NP, tested in $\mathrm{H}_{2}$ /air with a catalyst loading of $0.2 \mathrm{mg}_{\mathrm{Pt}} \mathrm{cm}^{-2}$. The output of power performance trend follows the order of $\mathrm{Au}-\mathrm{AgPt} \mathrm{NR} / \mathrm{C} \mathrm{B}<$ $\mathrm{Pt} / \mathrm{C}<\mathrm{AgPt}$ NR/C $<\mathrm{Au}-\mathrm{AgPt}$ NR/C A with peak power densities of $0.41,0.48,0.52$ and $0.58 \mathrm{~W} \mathrm{~cm}^{-2}$, respectively. The enhanced power performance for $\mathrm{Au}-\mathrm{AgPt} \mathrm{NR} / \mathrm{C}$ A indicates a positive effect of the Au integration on the AgPt alloy NR catalyst toward the ORR. This enhancement also depends on the arrangement of $\mathrm{Pt}, \mathrm{Ag}$ and $\mathrm{Au}$ atoms along the NRs. $\mathrm{Au}-\mathrm{AgPt} \mathrm{NR} / \mathrm{C} \mathrm{B}$ containing the same composition as $\mathrm{Au}-\mathrm{AgPt} \mathrm{NR} / \mathrm{C}$ A exhibits the lowest power performance because of its higher percentage of $\mathrm{Au}$ and $\mathrm{Ag}$ on the NR surface (Table 1).
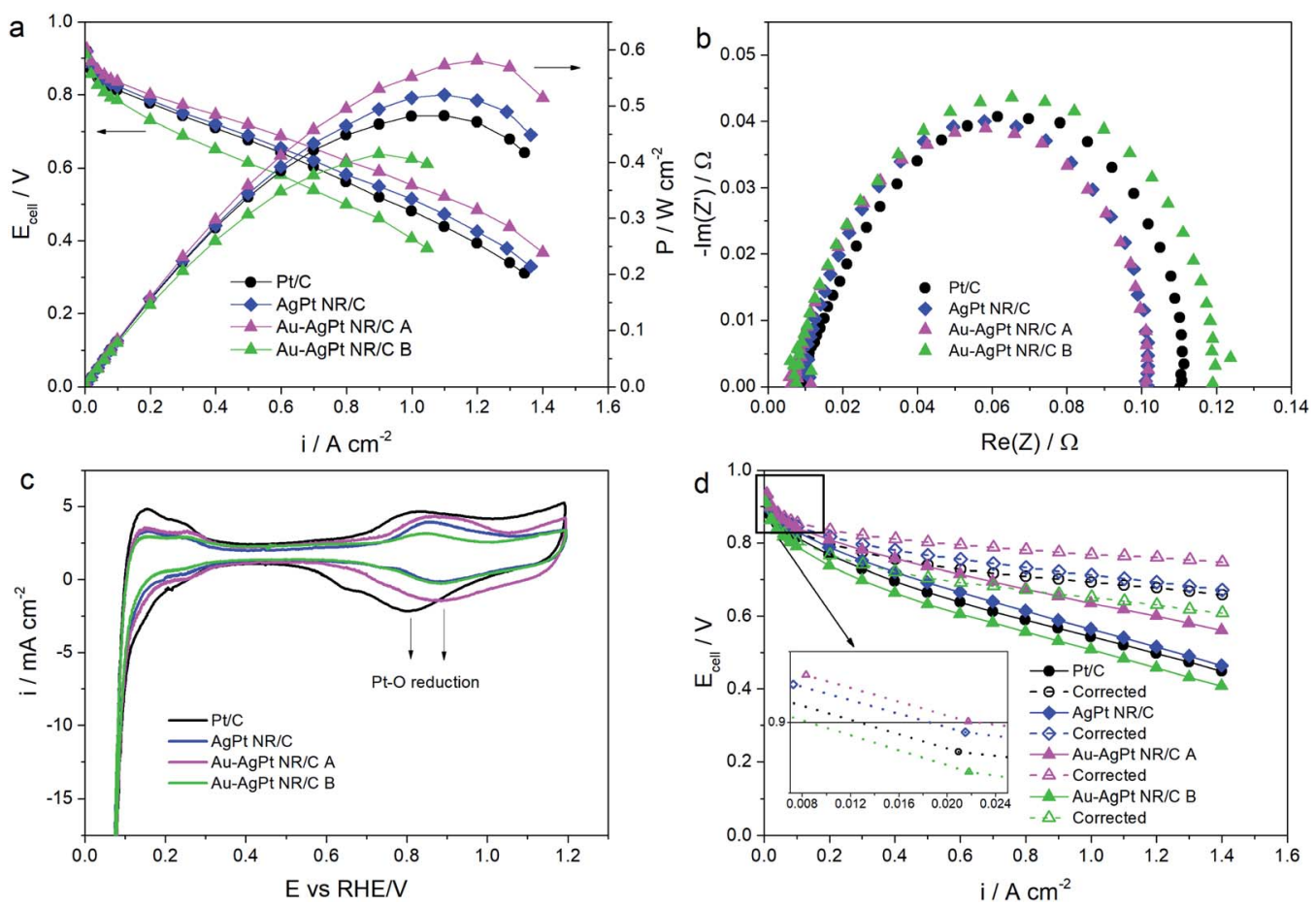

Fig. 4 Power performance comparison of the MEAs with the cathode catalysts of AgPt NR/C and 5 at\% Au integrated AgPt NR/C and Pt/C: (a) polarization and power density curves recorded at $80^{\circ} \mathrm{C}$ in fully humidified $\mathrm{H}_{2}$ /air at an absolute pressure of $2.5 / 2.3$ bar and stoichiometric ratio of 1.3/1.5, respectively; (b) corresponding EIS spectra at $30 \mathrm{~mA} \mathrm{~cm}{ }^{-2}$ with an amplitude of $4.5 \mathrm{~mA} \mathrm{~cm}^{-2}$ in the frequency range of $10 \mathrm{k}-0.1 \mathrm{~Hz}$; (c) cathode CVs recorded between 0.05 and $1.2 \mathrm{~V}$ at a scan rate of $20 \mathrm{mV} \mathrm{s}^{-1}$ under $\mathrm{H}_{2} / \mathrm{N}_{2}$, and (d) the original and corrected polarization curves obtained under $\mathrm{H}_{2} / \mathrm{O}_{2}$ testing at an absolute pressure of 1.5/1.5 bar and a stoichiometric ratio of 2/9.5. 
The EIS analysis result at a low current density of $30 \mathrm{~mA}$ $\mathrm{cm}^{-2}$ (Fig. 4b) supports the obtained polarization curves. The MEAs made of the AgPt NR/C and $\mathrm{Au}-\mathrm{AgPt} \mathrm{NR} / \mathrm{C}$ A catalysts show very close semi-circles, confirming a similar charge transfer resistance, which is smaller than that of $\mathrm{Pt} / \mathrm{C}$. The largest impedance was recorded for $\mathrm{Au}-\mathrm{AgPt} \mathrm{NR} / \mathrm{C} \mathrm{B}$, indicating its poorest kinetic activity. This output further reveals that the enhanced ORR performance in operating fuel cells is mainly derived from the superior intrinsic properties of the catalyst induced by the architecture of the single-crystal 1D nanostructure and alloy composition. The 1D morphology provides enhanced electron transport paths and the catalyst layer from 1D nanostructures possesses a high porosity ratio facilitating the oxygen mass transport. ${ }^{15}$ Therefore, improved power performance is expected at the large current density region from the MEA made of Au-AgPt NR/C A with longer NRs, which is confirmed by the EIS spectra at larger current densities (low potentials) recorded at 0.65 and $0.5 \mathrm{~V}$ (Fig. S6 $\dagger$ ).

The polarization and power density curves of the MEAs made of the $\mathrm{Au}-\mathrm{AgPt} \mathrm{NR} / \mathrm{C} \mathrm{A}$ catalysts with various $\mathrm{Au}$ contents are also shown in Fig. S7a and b. $\dagger$ Enhanced power performance is recorded with the integration of $\mathrm{Au}$, reaching the highest power density at 5 at $\% \mathrm{Au}$. The power densities at an operational voltage of $0.6 \mathrm{~V}$ are 0.48 and $0.52 \mathrm{~W} \mathrm{~cm}^{-2}$ for the catalysts containing 2 and 5 at\% Au, respectively. Further increase of the $\mathrm{Au}$ content results in a decreased power density, and it drops to $0.41 \mathrm{~W} \mathrm{~cm}^{-2}$ at 12 at\% $\mathrm{Au}$, which is even lower than that of $\mathrm{Pt}$ NR/C. The corresponding EIS spectra (Fig. S7d $\dagger$ ) show very close charge transfer resistances, indicating a similar kinetics activity for all catalysts. Even though the alloying degree is influenced by the concentrations of $\mathrm{Au}$ and $\mathrm{Ag}$ (Fig. S3†), their effect on the catalytic performance of $1 \mathrm{D}$ Pt alloy catalysts is less apparent than that of the arrangement of the metal within the alloyed structure (i.e. between $\mathrm{Au}-\mathrm{AgPt} \mathrm{NR} / \mathrm{C} \mathrm{A}$ and B).

ECSA representing the effective number of active catalytic sites for the ORR on the catalyst surface was determined from the $\mathrm{H}_{2}$ desorption peak of the cathode CV (Fig. 4c), and the values are listed in Table 2. The CV plots recorded in the MEA test show a similar trend to that from the half-cell RDE measurement (Fig:S8a $\dagger$ ). The commercial Pt/C nanoparticle catalyst exhibits a much larger value than the NR catalysts. The smaller ECSA of the NR catalysts can be ascribed to the anisotropic morphology of the 1D nanostructures, which is in agreement with our previous study. ${ }^{42}$ The slightly larger ECSA of Au-AgPt NR/C A is attributed to the higher Pt distribution on the NR surface than that for AgPt NR/C, which has been confirmed by the XPS analysis result (Table 1). Meanwhile, a lower ECSA for Au-AgPt NR/C B is related to the high

Table 2 ECSA, mass activity (MA) and specific surface activity (SA) toward the ORR for the as-prepared catalysts recorded in the MEA test

\begin{tabular}{llll}
\hline Catalyst & $\mathrm{ECSA} / \mathrm{m}^{2} \mathrm{~g}_{\mathrm{Pt}}{ }^{-1}$ & $\mathrm{MA} / \mathrm{A} \mathrm{mg}_{\mathrm{Pt}}{ }^{-1}$ & $\mathrm{SA} / \mu \mathrm{A} \mathrm{cm}{ }^{-2}$ \\
\hline $\mathrm{Pt} / \mathrm{C}$ & 50.67 & 0.065 & 130.29 \\
$\mathrm{AgPt} \mathrm{NR/C}$ & 24.17 & 0.095 & 378.57 \\
$\mathrm{Au}-\mathrm{AgPt} \mathrm{NR} / \mathrm{C} \mathrm{A}$ & 25.98 & 0.110 & 425.22 \\
$\mathrm{Au}-$ AgPt NR/C B & 21.73 & 0.050 & 204.76
\end{tabular}

distribution of $\mathrm{Au}$ on the NR surface blocking the active catalytic sites, which was also reported in another study. ${ }^{31}$ This phenomenon is also found in the $\mathrm{Au}-\mathrm{AgPt} \mathrm{NR} / \mathrm{C}$ catalysts with a high $\mathrm{Au}$ content prepared by following reaction scheme A. The CV plots and ECSA values are compared for the $\mathrm{Au}-\mathrm{AgPt} \mathrm{NR} / \mathrm{C}$ with various $\mathrm{Au}$ contents and shown in Fig. S9. $\dagger \mathrm{A}$ higher $\mathrm{Au}$ content induces more $\mathrm{Au}$ deposition on the NR surface (Fig. S4 $\dagger$ ), resulting in less exposure of the active Pt sites. Hence, a lower ECSA is observed (down to 21.37 and $18.34 \mathrm{~m}^{2} \mathrm{~g}_{\mathrm{Pt}}{ }^{-1}$ at 8 and $12 \mathrm{at} \% \mathrm{Au}$, respectively). These results demonstrate that a large ECSA is also preferred for the NR catalysts to minimize the voltage losses to achieve enhanced power performance. This also implies the limitation of applying a high $\mathrm{Au}$ content to further improve the catalytic performance of the $\mathrm{Au}-\mathrm{AgPt}$ alloy nanorod catalysts.

Fig. 4 d shows the polarization curves obtained under $\mathrm{H}_{2} / \mathrm{O}_{2}$, and they were corrected with the $\mathrm{H}_{2}$-crossover current density and ohmic resistance loss (Fig. S10 $\dagger$ ) based on the method described by Gasteiger et al. ${ }^{43}$ The measured activities of the catalysts are summarized in Table 2 . The highest mass activity is $0.110 \mathrm{~A} \mathrm{mg}_{\mathrm{Pt}}{ }^{-1}$ at $0.9 \mathrm{~V}$ for $\mathrm{Au}-\mathrm{AgPt} \mathrm{NR} / \mathrm{C} \mathrm{A}$, which is 1.15 and 1.7-fold higher than that of AgPt NR/C and Pt/C, respectively. For comparison, ORR mass and specific activities of $0.305 \mathrm{~A}$ $\mathrm{mg}_{\mathrm{Pt}}{ }^{-1}$ and $1078.78 \mu \mathrm{A} \mathrm{cm}^{-2}$ are achieved for $\mathrm{Au}-\mathrm{AgPt} \mathrm{NR} / \mathrm{C} \mathrm{A}$ in the RDE measurement (Fig. S8d and $\mathrm{e}^{\dagger}$ ). These values are 1.5 and 4.4-fold higher than the $0.198 \mathrm{~A} \mathrm{mg}_{\mathrm{Pt}}{ }^{-1}$ and $254.11 \mu \mathrm{A} \mathrm{cm}^{-2}$ of the commercial Pt/C catalyst, respectively. A higher ORR activity obtained in the RDE measurement is commonly observed because of the harsher environment during the PEMFC operation. ${ }^{3,44}$ Nevertheless, the results from both techniques show a similar trend, confirming the identical catalytic response of the tested catalysts toward the ORR.

The complexity of the MEA test in single fuel cells includes the resistances corresponding to proton transport across the catalyst layers and membrane, mass transfer of gases and water throughout the catalyst layers, etc. Such conditions are less represented in the clean environment of RDE measurement in liquid electrolytes. So far, only a few advanced shapecontrolled catalysts have been successfully made for the MEA test. Pan et al. reported the realization of shape-controlled Pt hybrid catalysts in the MEA test under $\mathrm{H}_{2} / \mathrm{O}_{2}$ and $\mathrm{H}_{2} /$ air. ${ }^{23}$ When utilising an ultra-low Pt loading, most of the shapecontrolled Pt hybrid catalysts exhibited a higher mass activity at $0.9 \mathrm{~V}$ than the commercial $\mathrm{Pt} / \mathrm{C}$ catalyst. However, very few of them outperform the $\mathrm{Pt} / \mathrm{C}$ catalyst at a fuel cell operational voltage of $0.6 \mathrm{~V}$ under $\mathrm{H}_{2}$ /air feeds. Such an issue is successfully addressed in this work, which further signifies the effectiveness of the ultrafine 1D Pt-hybrid nanostructure catalysts to optimize the ORR activities and mass transport characteristics in PEMFCs.

The enhanced catalytic activity of $\mathrm{Au}-\mathrm{AgPt} \mathrm{NR} / \mathrm{C} \mathrm{A}$ is first ascribed to its increased ECSA after the integration of $\mathrm{Au}$, which is induced by the high distribution of Pt on the NR surface. Second, the presence of $\mathrm{Au}$ provides a tensile strain to the Pt and $\mathrm{Ag}$ lattice, resulting in a modified electronic structure as shown by the XPS analysis results in Fig. 3c and d. It has also been a strategy to optimize the binding affinity of the $\mathrm{O}$ containing species on $\mathrm{Pt}$ at a certain degree, to escalate the 
catalytic kinetics activity. ${ }^{45,46}$ This is reflected in the cathode CVs in Fig. 4c. Positive shifts of the Pt oxygen reduction peak are recorded for the $\mathrm{NR}$ catalysts compared to $\mathrm{Pt} / \mathrm{C}(0.805 \mathrm{~V} v s$. RHE), linked to the weakening bond between the O-containing species and $\mathrm{Au}-\mathrm{AgPt}$ NRs for the enhanced ORR performance. To be more specific, the Pt-O reduction peaks of AgPt NR/C and $\mathrm{Au}-\mathrm{AgPt} \mathrm{NR} / \mathrm{C} \mathrm{A}$ are located at $0.894 \mathrm{~V}$ and $0.901 \mathrm{~V} v s$. RHE, respectively, further indicating the positive effect of the $\mathrm{Au}$ integration towards the ORR. Apart from the enhancement provided by the Au integration, the structure of 1D morphology also contributes to the improved catalytic activity. It offers preferential exposure of fewer low-coordination sites thus facilitating a better ORR kinetics rate. ${ }^{39}$

The main enhancement of the $\mathrm{Au}-\mathrm{AgPt} \mathrm{NR} / \mathrm{C}$ catalyst is more significant toward its stability in fuel cell operation. This was evaluated using an ADT in MEAs by potential sweeping between 0.6 and $1.2 \mathrm{~V}$ at a scan rate of $100 \mathrm{mV} \mathrm{s}^{-1}$ for 5000 cycles. Comparison between the polarization curves before and after the ADT are shown in Fig. 5a. The recorded peak power densities after the ADT are $0.28,0.26$ and $0.35 \mathrm{~W} \mathrm{~cm}^{-2}$ for the MEAs with the cathode catalysts Pt/C, AgPt NR/C and Au-AgPt NR/C A, respectively, further revealing the positive effect of the $\mathrm{Au}$ integration on the electrode durability. This is also demonstrated from the results for the MEAs with the cathode catalysts with various Au contents (Fig. S11†). The degradation ratio decreases with the increase of Au content, and the power density decline ratio is only $39.17 \%$ at 8 at $\% \mathrm{Au}$ after the ADT compared to the initial value, which is even lower than the power density loss of monometallic Pt NR/C (41.41\%). To further monitor the stability of the as-prepared catalysts, comparison of the cathode $\mathrm{CV}$ plots recorded before and after the $\mathrm{ADT}$ and the ECSA decline ratios are shown in Fig. 5b. The NR alloy catalysts show a lower ECSA decline ratio than $\mathrm{Pt} / \mathrm{C}$, intensifying the higher stability of the $1 \mathrm{D}$ nanostructures. The ECSA loss is improved to $51.20 \%$ at the 5 at $\%$ $\mathrm{Au}$ content from the $62.12 \%$ of $\mathrm{AgPt} \mathrm{NR} / \mathrm{C}$, and this is further minimized to $47.59 \%$ at 8 at\% $\mathrm{Au}$ (Fig. S12 $\dagger$ ). This finding explains the role of Au in preventing the surface area loss, which contributes to minimizing the power performance drop during the ADT in the MEA test.

$>$ The superior stability of 1D Pt nanostructured catalysts in PEMFCs has been widely reported in the literature. ${ }^{\mathbf{1 4 , 4 2 , 4 8 , 4 9}}$
However, further approaches to enhance the catalytic activity of the 1D Pt nanostructures through alloying remain a challenge because of the stability issue of the alloyed metals. ${ }^{8}$ Our previous studies demonstrated a more pronounced degradation mechanism of the bimetallic 1D Pt nanostructures hybridized with $\mathrm{Ag}$ and $\mathrm{Ni},{ }^{24,50}$ induced by the atomic segregation and susceptibility of the transition metals to oxidation in electrochemical reaction under acidic conditions. Hence, the bimetallic 1D nanostructures showed an about 10\% larger ECSA loss after the ADT than their monometallic counterpart. In this work, a comparable ECSA loss to that of Pt NR/C (52.04\%) is observed for 5 at\% Au-AgPt NR/C A (52.20\%). This further signifies the effectiveness of the $\mathrm{Au}$ integration to minimise the segregation and deformation of the 1D Pt-hybrid nanostructures.

The introduction of Au into AgPt NR/C changes the chemical and electrical properties of the 1D catalyst as shown by the XPS analysis results (Fig. 3c and d), which contributes not only to the catalytic activities but also its stability. A positive shift of the Pt binding energy after combining with 5 at\% Au can be an indication of the increased Pt interaction (i.e. Pt-Pt, Pt-Ag and PtO). ${ }^{47}$ Consequently, it decreases the unstable high-energy Pt and $\mathrm{Ag}$ sites, promoting immunity to the surface area loss during the ADT in the fuel cell environment. Therefore, the NR structure of Au-AgPt NRs is more retained than that of AgPt NRs after the ADT (Fig. 6). Meanwhile, the destruction of the 1D AgPt nanostructures and aggregation are highly distinguished in the absence of $\mathrm{Au}$, leading to the larger surface area loss and power performance drop after the ADT, which further manifests the stability issue of the alloy catalysts. Even though catalyst degradation and power performance decline cannot be fully avoided in PEMFC operation, the Au integration has successfully shown the improvement in the ECSA loss and structure degradation, which has been a major contribution to addressing the durability issue. Furthermore, the effectiveness of combining Au with the AgPt alloy catalyst to upgrade its catalytic activity and stability highly depends on the atomic arrangement and quantity of the $\mathrm{Au}$ content, and a good strategy is necessary to balance the enhancement in both activity and stability.
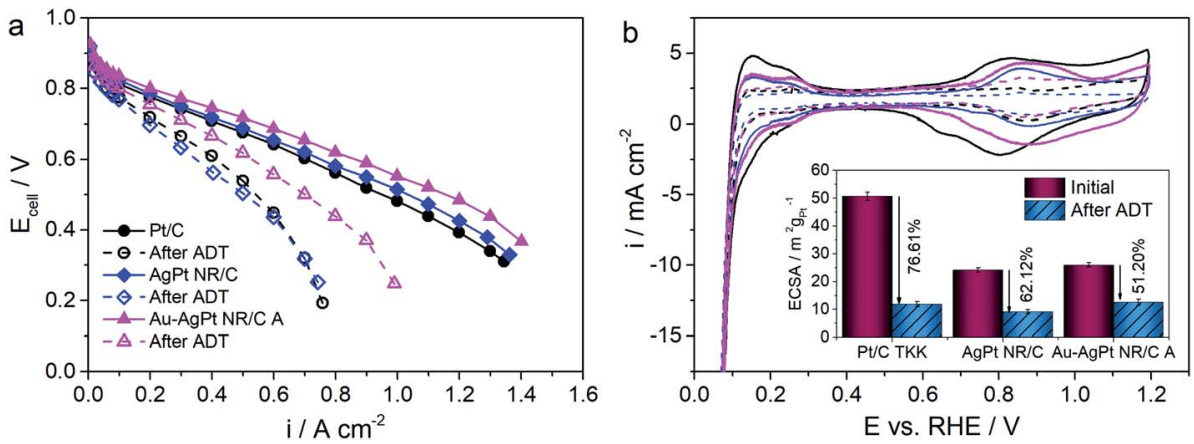

Fig. 5 (a) Polarization curves recorded before and after the accelerated degradation test (ADT) for the MEAs with the cathode catalyst made of $\mathrm{AgPt} / \mathrm{C}$ NR and Au-AgPt NR/C A in comparison to commercial Pt/C. (b) Comparison of cathode CV plots before and after the ADT with the corresponding ECSA decline ratio (inset). The ADT was performed using potential sweeping between 0.6 and $1.2 \mathrm{~V}$ at a scan rate of $100 \mathrm{mV} \mathrm{s}^{-1}$ for 5000 cycles with $\mathrm{H}_{2} / \mathrm{N}_{2}$. 


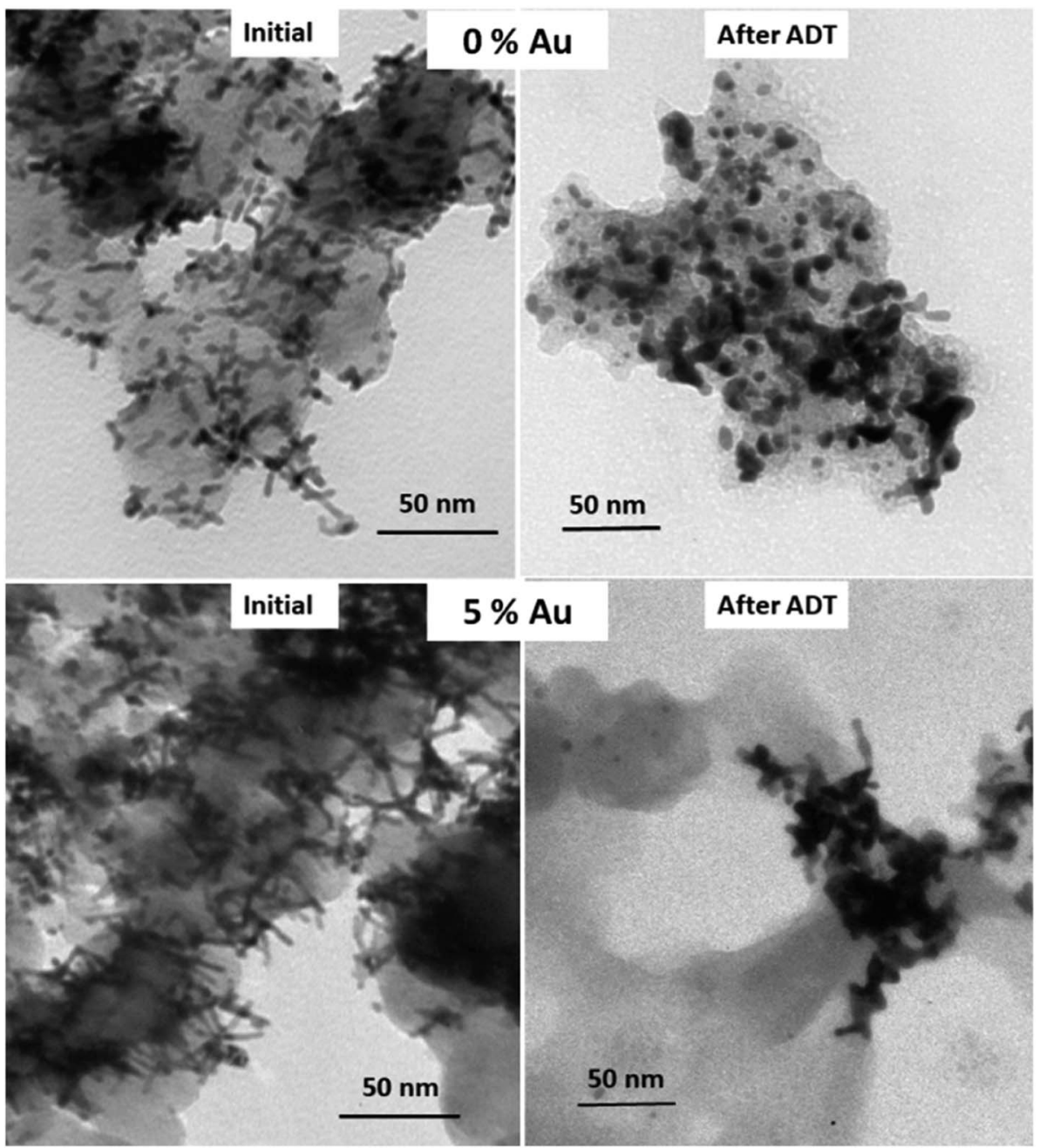

Fig. 6 TEM images of AgPt NR/C and Au-AgPt NR/C A before and after the ADT

\section{Conclusion}

In conclusion, a strategy is demonstrated by developing $1 \mathrm{D}$ $\mathrm{Au}$ integrated AgPt alloy nanorod catalysts with enhanced catalytic activities and stability in PEMFCs. A precise control of the $\mathrm{Au}$ integration process is crucial for regulating the catalyst structure. Introducing Au ions at an early reaction state is preferred to optimize Pt deposition on the nanostructure surface. The presence of Au tunes the reduction process during the growth of the 1D AgPt alloy, leading to longer NRs and thus enhanced mass transport performance for higher fuel cell power performance. The Au-AgPt NR/C A catalyst with 5 at\% Au shows 1.12- and 1.2-fold higher peak power density, and 1.15- and 1.7-fold higher mass activity than the AgPt NR/C and $\mathrm{Pt} / \mathrm{C}$ catalysts in the MEA test, respectively. A significantly enhanced effect of the Au integration is observed for the catalyst stability during PEMFC operation. The Au-AgPt NR/C catalyst exhibits a power density and an ECSA decline ratio of $39.63 \%$ and $51.20 \%$ after the ADT, respectively, which are much less than the $49.71 \%$ and $62.12 \%$ of AgPt NR/C and $44.19 \%$ and $76.61 \%$ of Pt/C. The increasing Au content can effectively reduce the ECSA loss during the ADT, but a high content blocks the catalytically active sites on the NR surface, finally resulting in poor fuel cell power performance. It is anticipated that the understanding obtained from the $\mathrm{Au}$ integration for $\mathrm{NR}$ catalysts in this work can help the design and development of practical shape-controlled alloy catalysts for PEMFCs.

\section{Conflicts of interest}

There are no conflicts to declare.

\section{Acknowledgements}

This work is part of E. Fidiani PhD studentship sponsored by the Indonesian Endowment Fund for Education (LPDP) and the EPSRC Centre for Doctoral Training in Fuel Cells and their Fuels (EP/L015749/1).

\section{References}

1 Y. Wang, K. S. Chen, J. Mishler, S. C. Cho and X. C. Adroher, Appl. Energy, 2011, 88, 981-1007. 
2 T. Yoshida and K. Kojima, Electrochem. Soc. Interface, 2015, 24, 45-49.

3 M. K. Debe, Nature, 2012, 486, 43-51.

4 Y. T. Pan, L. Yan, Y. T. Shao, J. M. Zuo and H. Yang, Nano Lett., 2016, 16, 7988-7992.

5 D. Banham and S. Ye, ACS Energy Lett., 2017, 2, 629-638.

6 K. Jayasayee, J. A. R. Van Veen, T. G. Manivasagam, S. Celebi, E. J. M. Hensen and F. A. de Bruijn, Appl. Catal., B, 2012, 111112, 515-526.

7 F. Maillard, L. Dubau, J. Durst, M. Chatenet, J. André and E. Rossinot, Electrochem. Commun., 2010, 12, 1161-1164.

8 Y. Hoshi, T. Yoshida, A. Nishikata and T. Tsuru, Electrochim. Acta, 2011, 56, 5302-5309.

9 L. Dubau, M. Lopez-Haro, L. Castanheira, J. Durst, M. Chatenet, P. Bayle-Guillemaud, L. Guétaz, N. Caqué, E. Rossinot and F. Maillard, Appl. Catal., B, 2013, 142-143, 801-808.

10 S. Chen, H. A. Gasteiger, K. Hayakawa, T. Tada and Y. ShaoHorn, J. Electrochem. Soc., 2010, 157, A82.

11 J. C. Meier, C. Galeano, I. Katsounaros, A. A. Topalov, A. Kostka, F. Schüth and K. J. J. Mayrhofer, ACS Catal., 2012, 2, 832-843.

12 K. Yu, D. J. Groom, X. Wang, Z. Yang, M. Gummalla, S. C. Ball, D. J. Myers and P. J. Ferreira, Chem. Mater., 2014, 26, 5540-5548.

13 H. Lv, J. Wang, Z. Yan, B. Li, D. Yang and C. Zhang, Fuel Cells, 2017, 17, 635-642.

14 B. Li, D. C. Higgins, Q. Xiao, D. Yang, C. Zhng, M. Cai, Z. Chen and J. Ma, Appl. Catal., B, 2015, 162, 133-140.

15 Y. Lu, S. Du and R. Steinberger-Wilckens, Appl. Catal., B, 2016, 199, 292-314.

16 M. Li, Z. Zhao, T. Cheng, A. Fortunelli, C. Y. Chen, R. Yu, Q. Zhang, L. Gu, B. V. Merinov, Z. Lin, E. Zhu, T. Yu, Q. Jia, J. Guo, L. Zhang, W. A. Goddard, Y. Huang and X. Duan, Science, 2016, 354, 1414-1419.

17 J. N. Tiwari, R. N. Tiwari and K. S. Kim, Prog. Mater. Sci., 2012, 57, 724-803.

18 Y. Lu, Y. Jiang and W. Chen, Nano Energy, 2013, 2, 836-844.

19 Y. T. Liang, S. P. Lin, C. W. Liu, S. R. Chung, T. Y. Chen, J. H. Wang and K. W. Wang, Chem. Commun., 2015, 51, 6605-6608.

20 Y. C. Tseng, H. S. Chen, C. W. Liu, T. H. Yeh and K. W. Wang, J. Mater. Chem. A, 2014, 2, 4270-4275.

21 N. N. Kariuki, W. J. Khudhayer, T. Karabacak and D. J. Myers, ACS Catal., 2013, 3, 3123-3132.

22 A. Kongkanand and M. F. Mathias, J. Phys. Chem. Lett., 2016, 7, 1127-1137.

23 L. Pan, S. Ott, F. Dionigi and P. Strasser, Curr. Opin. Electrochem., 2019, 18, 61-71.

24 E. Fidiani, G. Thirunavukkarasu, Y. Li, Y.-L. Chiu and S. Du, J. Mater. Chem. A, 2020, 8, 11874-11883.

25 Y. Ma and P. B. Balbuena, Surf. Sci., 2008, 602, 107-113.

26 Y. T. Liang, S. P. Lin, C. W. Liu, S. R. Chung, T. Y. Chen, J. H. Wang and K. W. Wang, Chem. Commun., 2015, 51, 6605-6608.
27 J. Choi, J. Cho, C. W. Roh, B. S. Kim, M. S. Choi, H. Jeong, H. C. Ham and H. Lee, Appl. Catal., B, 2019, 247, 142-149.

28 A. Dorjgotov, Y. Jeon, J. Hwang, B. Ulziidelger, H. S. Kim, B. Han and Y. G. Shul, Electrochim. Acta, 2017, 228, 389-397.

29 M. Gatalo, P. Jovanovič, G. Polymeros, J.-P. Grote, A. Pavlišič, F. Ruiz-Zepeda, V. S. Šelih, M. Šala, S. Hočevar, M. Bele, K. J. J. Mayrhofer, N. Hodnik and M. Gaberšček, ACS Catal., 2016, 6, 1630-1634.

30 C. Wang, D. Van Der Vliet, K. L. More, N. J. Zaluzec, S. Peng, S. Sun, H. Daimon, G. Wang, J. Greeley, J. Pearson, A. P. Paulikas, G. Karapetrov, D. Strmcnik, N. M. Markovic and V. R. Stamenkovic, Nano Lett., 2011, 11, 919-926.

31 J. Zhang, K. Sasaki, E. Sutter and R. R. Adzic, Science, 2007, 315, 220-222.

32 C. E. Kim, D. H. Lim, J. H. Jang, H. J. Kim, S. P. Yoon, J. Han, S. W. Nam, S. A. Hong, A. Soon and H. C. Ham, J. Chem. Phys., 2015, 142, 034707.

33 K. Sasaki, H. Naohara, Y. Choi, Y. Cai, W. F. Chen, P. Liu and R. R. Adzic, Nat. Commun., 2012, 3, 1115.

34 L. L. Shen, G. R. Zhang, S. Miao, J. Liu and B. Q. Xu, ACS Catal., 2016, 6, 1680-1690.

35 Y. Kang, J. Snyder, M. Chi, D. Li, K. L. More, N. M. Markovic and V. R. Stamenkovic, Nano Lett., 2014, 14, 6361-6367.

36 G. Tsotridis, A. Pilenga, G. De Marco and T. Malkow, EU Harmonised Test Protocols for PEMFC MEA Testing in Single Cell Configuration for Automotive Applications, JRC Science for Policy Report, 2015.

37 C. Busó-Rogero, A. Ferre-Vilaplana, E. Herrero and J. M. Feliu, Electrochem. Commun., 2019, 98, 10-14.

38 C. Tojo, D. Buceta and M. A. López-Quintela, J. Phys. Chem. C, 2018, 122, 20006-20018.

39 S. Sun, G. Zhang, D. Geng, Y. Chen, R. Li, M. Cai and X. Sun, Angew. Chem., Int. Ed., 2011, 50, 422-426.

40 X. Xie, G. Gao, S. Kang, T. Shibayama, Y. Lei, D. Gao and L. Cai, Adv. Mater., 2015, 27, 5573-5577.

41 C. Fang, J. Zhao, G. Zhao, L. Kuai and B. Geng, Nanoscale, 2016, 8, 14971-14978.

42 Y. Lu, S. Du and R. Steinberger-Wilckens, Appl. Catal., B, 2015, 164, 389-395.

43 H. A. Gasteiger, S. S. Kocha, B. Sompalli and F. T. Wagner, Appl. Catal., B, 2005, 56, 9-35.

44 L. Chong, J. Wen, J. Kubal, F. G. Sen, J. Zou, J. Greeley, M. Chan, H. Barkholtz, W. Ding and D. J. Liu, Science, 2018, 362, 1276-1281.

45 V. Stamenkovic, B. S. Mun, K. J. J. Mayrhofer, P. N. Ross, N. M. Markovic, J. Rossmeisl, J. Greeley and J. K. Nørskov, Angew. Chem., Int. Ed. Engl., 2006, 45, 2897-2901.

46 M. P. Hyman and J. W. Medlin, J. Phys. Chem. C, 2007, 111, 17052-17060.

47 W. An and P. Liu, ACS Catal., 2015, 5, 6328-6336.

48 B. Li, Z. Yan, D. C. Higgins, D. Yang, Z. Chen and J. Ma, J. Power Sources, 2014, 262, 488-493.

49 P. Mardle, X. Ji, J. Wu, S. Guan, H. Dong and S. Du, Appl. Catal., B, 2020, 260, 118031.

50 P. Mardle, G. Thirunavukkarasu, S. Guan, Y. L. Chiu and S. Du, ACS Appl. Mater. Interfaces, 2020, 12, 42832-42841. 